\title{
Anterior Tibial Artery
}

National Cancer Institute

\section{Source}

National Cancer Institute. Anterior Tibial Artery. NCI Thesaurus. Code C12825.

An artery of the lower extremity that supplies blood to the anterior part of the leg and the foot. 